Nini Fang

https://doi.org/10.26881/ae.2019.16.10

ORCID: 0000-0001-8730-8582

University of Edinburgh

Elizabeth O'Brien

ORCID: 0000-0002-0162-9754

University College Dublin

Anne Pirrie

ORCID: 0000-0002-3141-3786

University of the West of Scotland

Anne.Pirrie@uws.ac.uk

\title{
Care, contingency and capability: ecological perspectives on higher education
}

\section{Introduction}

This contribution to Ars Educandi builds upon previous work conducted in the spirit of creative-relational inquiry (Pirrie and Fang 2019). That article addressed the complex ecology of contemporary higher education, and gestured towards study practices (Schildermans 2019) that might prove ameliorative in the long run. These were encapsulated by the relational ethics that were the hallmark of our collaboration, in our way of being of and for the university, and in the manner in which "we [enacted] a relation between the university and the world by convoking matters of study" (Schildermans 2019: 138). It is not our intention here to present practical hints or "solutions" (extract from the Call for Papers for this issue) that might facilitate more fruitful and rewarding collaboration between academics. Rather, we believe that collaboration between colleagues across lines of difference transcends instrumental considerations and can only flourish in the ever-diminishing but somehow persistent fallow spaces of the institutional environment marred by over-regulation. In the article referred to above we focused on the damaging effects of the student satisfaction agenda, particularly its impact on teachers' subjectivity (see also Pirrie and Day 2019; Day and Pirrie 2019; see Pirrie 2019 for a broader account of the malaise in contemporary higher education written from 
the perspective of one who navigates through it, attentive to wind and tide). As is so often the case in academic work in the humanities and social sciences, the article by Pirrie and Fang (2019) raised more questions about our understanding of our role and place in the university than we were able to address within its modest scope. A salutary reminder, in the event that one were needed, that "knowledge knocks against the cold scope of ignorance, like sunbeams on the mirroring sea, dumfounded by its depth" (Jabès 1996: 6). So we take to the waters again, three brave women in a leaking boat. This time we are rowing determinedly away from a sinking ship.

\section{Higher education from the inside out}

It may already be apparent to the attentive reader that we regard thinking as a collective affair, as making common cause around an issue of mutual concern. We consider thinking to be an inherently risky "entre-prise that is unamenable to metrics that depend on reductive quantification", particularly in respect of how academics spend their time (Papadopoulos 2017: 523). Rather, we consider thinking as something that is taken in hand, grasped between people, and that involves navigating "between the banks of self and world, habit and habitat" (Schildermans 2019: 145). Our three-women-in-a-boat adventure was conducted in a spirit of mutual trust and openness towards the other. It entailed a "process of thinking ... that is capable of ruminating, objecting ... [that is] recalcitrant" (Schildermans 2019: 141) rather than one that is conciliatory, conformist, and unequivocally ameliorative in intent. We came to think together, that we might sail on to be still.

In respect of both form and content, the current article encapsulates our enduring commitment to considering issues that impact upon academic practice from the inside out rather than from the outside in. It appears that much of the literature that explores the conditions in higher education that militate against research collaboration is written from the latter perspective. We suggest that a thorough examination of research cooperation, which is the theme of this issue of Ars Educandi, is premised upon due consideration of exteriority and interiority. We thus take the view that accounts that foreground lived experience, the ruminations of common sense (Schildermans 2019: 139) (our emphasis) and the process of feeling one's way from within are just as valid as more conventional scientific explorations of the corrosive impact of performative technologies, to take but one example. We privilege the former in this article, that is to say a commoning of inside-out perspectives. Our way of working from the inside out revolves around the stories that we tell ourselves and the stories that we tell to others, including the one we set before you here.

At this point a brief note on the authors is called for, given that the focus in this issue of Ars Educandi is on interdisciplinarity and cooperation between academics 
from different backgrounds and at different stages of their careers. These factors certainly apply in our case. Nini has a background in counselling and psychotherapy; Annie started out in the humanities and has long since migrated into the field of education. The arrival of a third author, Elizabeth, who has a background in biomedical sciences and who taught mathematics before embarking upon her $\mathrm{PhD}$ on care in education, fortified us and made two into three. (This is our sole concession to metrics.) As a result, we became more determined than ever to "push back against ... accumulating what is measurable [and to] become engrossed in what counts" (O'Brien 2019). These are the key factors in our bid to "re-world" and re-inhabit the university. This latter project entails taking "the inseparability of habit and habitat as a point of departure" (Schildermans 2019: 144). It means making ourselves at home in the university, without becoming habituated to the performative technologies that endanger our environment and jeopardise our inter-personal relationships as scholars, colleagues and friends.

\section{Clearing the ground}

Perhaps we should begin by clarifying what we mean by performative technologies. Drawing upon Stephen Ball's extensive corpus of work relating to the mechanisms of performativity in education (Ball 2000, 2001, 2003, 2008, 2012, 2015), Englund and Gerdin (2019: 5) use the expression performative technologies as an umbrella term to refer to the "various forms of rankings and league tables, audits, performance measures and performance-related pay" that have disfigured higher education in recent decades, not only in the UK but also elsewhere in Europe and across the globe. There is now widespread consensus in the research literature that technologies that were originally introduced to enhance "productivity" have resulted in forms of performative or neoliberal subjectivities that adhere "to the ideals that performative technologies invoke [and have become] highly outcome-oriented" (Englund and Gerdin 2019: 503). It is important to note that the influence of performative technologies extends far beyond providing avenues and leverage for getting things done, or, in contemporary education-speak, for achieving pre-determined (learning) outcomes or meeting specific targets. As Ball (2015:258) points out in the context of higher education, performative technologies play a key role in the construction of the neoliberal subject as "striving, responsible, competitive, enterprising". Needless to say, these are qualities that do not always serve to promote the forms of authentic and caring collaboration across lines of difference that animate us, and that have mobilized us, here, as co-authors. Rather, they invoke an image of every man (sic) for himself. These qualities also reduce the scope for looking sideways, for making room for the fleeting and contingent and for attending to the liminal, i.e. what lies between us or in the margins of our awareness.

We do not intend to reprise the lines of argument developed by others, as this would serve no purpose other than to establish our credentials, which we regard 
as a rather dreary exercise in performativity. For our current purposes it will suffice to point out that valuable ground work has been conducted in respect of theorizing managerialism in relation to higher education, and exploring its relation to cognate concepts such as neoliberalism and New Public Management (Shepherd 2017; see also Ward 2011; and Raaper 2016, 2017, 2018, 2019 for in-depth investigations of the effects of the "neoliberal turn" in the increasingly complex and stratified higher education sector). As Papadopoulos (2017: 515) has pointed out with reference to the Australian university sector, "the confluence of mass expansion, marketisation and economic constraint re-constitutes universities as palimpsests of three institutional forms - bureaucracy, corporation and scholarly institution, each with its own logic". These competing institutionalised imperatives, which apply to varying degrees across the university sector in Europe and beyond, have given rise to tensions in strategy and practice that can play out as "conflicts between bureaucratic, corporate and scholarly logics" (Papadopoulos 2017: 215). They also invoke the plural identities that are subsumed by the word "academic" in contemporary higher education, a term that increasingly seems to imply reduced capacity for self-determination and self-direction, and, more importantly, for genuine collaboration across lines of difference.

Our aim here is rather more modest in scope: namely, to suggest that adopting a from-the-outside-in perspective and exploring (for instance) the mechanisms that enable performative technologies to be "transformed from pure 'technologies of domination' into 'technologies of the self'" (Englund and Gerdin 2019: 503, with reference to Foucault 1993) runs the risk of discursively (re-) producing the neoliberal subject as self-centred, compliant and, like the systems within which they operate, amenable to amelioration or perfectibility. More importantly, we believe that such a move reduces scope for contingency and unsuspected subversion, which are key and much neglected dimensions of the life of a scholar. "Outside-in" approaches also place obstacles in the way of cultivating different forms of academic writing, different ways of exploring professional and personal identity, and, last but not least, different ways of living our lives as academics. We write with and through each other in order to re-instate wonder, curiosity and care as key auxiliary virtues in the academic life; to embrace contingency as a core element of ethical working practices; and, frankly, pour encourager les autres. The latter seems ever more important in an era in which encouragement seems to be in short supply. In short, we believe that the more conventional "outside-in" perspectives reduce the scope for asking (ourselves) what we might become in the university (and, by implication, what might become of the university).

Smith (2016: 278) observes that "acquiring knowledge is often less important than learning to live with our knowledge". Schildermans (2019: 185) reiterates the question posed by Haraway (2016): „How do we stay with the trouble?”. This article is a testament to Smith's observation, and marks a collective endeavour to answer the deceptively simple question of how we stay with the trouble. We suggest 
that adopting a from-the-outside-in perspective greatly reduces the scope for "staying with the trouble" and providing an honest and personal snapshot of academic life. We speak and write unashamedly "from the perspective of mortal critters entwined in myriad unfinished configurations of places, times, matters, meanings" (Haraway 2016: 1). Staying with the trouble entails exploring rather than suppressing or smoothing over the contingent encounters that engendered this article, and examining their implications for the tenor of academic life in conditions of constraint. Paradoxical as it may seem, an approach from the outside in privileges both the formation of the self as a neoliberal subject and the discursive creation of a realm of study to which one owes allegiance and from which one claims credibility, leading to the maintenance of the status quo. The myriad unfinished configurations celebrated by Haraway are reduced to institutionalised networks posited on input-output models that produce a particular form of subjectivity: competitive, striving and compliant. In contrast, we believe that chance encounters that foreground attention and permit a movement from the inside out constitute more ethical and sustainable "study practices" and afford greater scope for care, contingency and capability in an increasingly professionalised higher education sector. As we shall see from Elizabeth's account of her conference experience, chance encounters experienced in a spirit of mutuality flourish in liminal spaces; they call us forth in our co-presence; and, last but not least, they install a "particular attitude towards life and [...] bring about a messianic interruption of time" that enables us to escape "a productive regime that does not tolerate that we lose ourselves, that we truly follow a passion" (Vlieghe and Zamojski 2017: 857). In short, they reinstate the value of a mate u rism. Perhaps even more importantly for our current purposes, such chance encounters and the associated ethic of practice provide the conceptual and moral resources to reinstate Whitehead's vision of the university as a home of adventure. This implies a rejection of the status $q u o$, namely the contemporary vision of the university as a productive regime and the site for the fulfilment of discrete, pre-ordained tasks executed with maximum efficiency along a predetermined time-line (to take the example that convoked our interest on this particular occasion). The reader will not be surprised to learn that we regard the latter view as an impoverished, partial and inadequate vision of what the university stands for, and what it is to have one's being in the university.

\section{Let the adventure begin}

In an address to mark the inauguration of the Harvard Business School in 1927, Alfred North Whitehead, philosopher and mathematician, spoke on the theme of "universities and their function". He argued that "universities should be homes of adventure shared in common by young and old" (Whitehead 1929: 98). As Schildermans (2019: 138) points out, the key term in that proposition - "homes of adventure - seems 
to imply a separation between an adventure that is inside the home and the world that is outside". This brings us back to the interplay between exteriority and interiority that is one of the leitmotifs of this article. It also raises the question of what it is to dwell, what it means to inhabit a space that affords us ample opportunity to care for ourselves, and to care for each other and for the world around us. For Nini and Annie, whose first co-writing enterprise was premised upon "venturing from home on a thread of a tune" (Pirrie and Fang 2019), the very notion of the university as a home of adventure seemed inherently problematic. Indeed, that article was premised on an exploration of the university as a home of misadventure. That article arose as a means of enabling Nini to give voice to the ethical violence to which she had been subjected during her previous employment at a university in England. For Annie, reading Kafka's "Der Aufbruch" (The Departure) during her time as an undergraduate in the Department of German in Edinburgh was a formative experience that has resounded down the decades. It has been a source of comfort during her long years of exile in the social sciences. She responded to Nini's call, saddled up and set out on an adventure with little or no idea of where that might lead. It could not have been otherwise. Here she reprises the brief and enigmatic tale from Kafka that encapsulates and expresses her view of the nature of intellectual endeavour:

A rider saddles his horse and makes ready to depart. He hears the sound of a trumpet in the distance and asks his servant what it means. The servant hasn't heard anything and is nonplussed. 'Where are you going?' asks the servant, bemused. 'I don't know', the rider explains. 'Away from here, only away from here, always away from here, that is my goal'. The servant is even more puzzled. 'But you haven't taken anything to eat with you!' The rider explains that he doesn't need anything. The journey is so long that he would starve to death if he didn't find anything to eat along the way. 'I'm not going to be saved by a packed lunch', he said. 'Luckily, it's a very long journey'. (After Kafka 1996)

And yet at some level the idea of making the university a home of adventures seems to us to make sense. The conversation that prompted us to write the present article was a written exchange between Nini and Annie in relation to the division of labour and the allocation of time in the university. "Perhaps the only way I can stop thinking about this is to think about it", Nini wrote. And think about it we did. And then we invited Elizabeth to join us, for contingent reasons that revolve around a chance encounter at a conference on a Greek island during which Elizabeth explored notions of care and capability.

\section{Higher education from the outside in}

Every time we open Google Scholar, we are exhorted to "stand on the shoulders of giants". This says a great deal about conventional understandings of the nature of academic practice. All too often this is characterized by an unthinking appeal 
to a higher authority ("what would Foucault have said?") and by the need to demonstrate mastery of a particular area of inquiry and/or body of knowledge. This appears to be de rigueur in a study culture disfigured by academic capitalism, where knowledge is all too often regarded as "in some sense objective, 'out there', a pile or hoard that exists whether anyone is tending to it or not and which any suitably energetic person can climb to the top of" (Collini 2012: 73). At the risk of stating the blindingly obvious (and what a revealing expression that is), to stand on the shoulders of giants is to run the risk of losing contact with the ground, the grounds, upon which we have our being. The focus of this issue of Ars Educandi is on the scale and quality of co-operation in the academy, with particular emphasis on collaboration between academics who are at different stages in their careers and who work across disciplinary differences. In this article we adopt an unashamedly inside-out perspective in order to foreground forms of inquiry that are guided by wonder, curiosity and care, and the ethical relations that underpin these auxiliary virtues. The issue of collective concern that initiated our shared adventure, and around which we will attempt to articulate our thoughts, is the unintended consequences of the wholesale implementation of workload allocation models (WAMs) in the UK higher education sector, and indeed elsewhere.

We hope to advance a more affirmative vision of working in the university, from the inside out, one that calls for "the inseparability of ethos, the way of behaving peculiar to a being, and oikos, the habitat of that being and the way in which that habitat satisfies or opposes the demands associated with the ethos or affords opportunities for an original ethos to risk itself" (Stengers 2005: 997, cited in Schildermans 2019: 143). So first we shall have Nini's story, and then Elizabeth's. Both have crafted unique and highly personal forms of speaking in an assembly, forged in and thorough dialogue. In the meantime, Annie flits around in the background, tidying up, or as Schildermans (2019: 157) would have it, "attending to matters of composition" and setting up correspondences. We use the term composition in the common or garden sense of attending to the composition of the text, as well as in the sense adumbrated by Schildermans (2019: 157), as follows: "The first art of composition has to do with the way in which people are brought together around something, and what kind of role they can assume in this gathering". For reasons that we need hardly explain here, the composition of this particular text (in the common or garden sense) does not conform entirely to the expected conventions of academic production". As Schildermans (2019: 158) points out, "there is the potential for hesitation, divergence and the risk of conflict [but] in spite of the presence of a matter of risk, the palaver is characterized by a specific kind

\footnotetext{
We have chosen to subvert conventional academic practice in respect of authorship. Annie may have set the ball rolling on this occasion, but the themes addressed in this article emerged in the course of synchronous and diachronous "dialogue" between all three authors. The particular "study practice" in respect of the order of names in the attributions for academic articles is derived from Dylan (1963).
} 
of trust". It is precisely this kind of trust that led Pirrie and Fang (2019) to observe that something might happen without being in a position to determine in advance the nature of that particular event. The unexpected arrival of Elizabeth in this article is a case in point. Hans Schildermans (2019: 158), who was our colleague on Tilos and whom we have unashamedly drawn into our palaver, concludes his exploration of composition with the following observations:

The art of composition fosters a mutual sensibility and readiness to be affected by a question. It brings people together in a way that undoes both personal intentions and general solutions, in order to make them susceptible for ... interdependent co-becoming. It is a composition without composer, and definitely without a transcendent position from which... to evaluate what has been composed (our emphasis).

But now we come back to earth...

\section{WAM! Bang! Crash!}

So endeth the lesson of reverie and rumination rooted in common sense; and so beginneth the setting of the problem. This "involves the question of how something - a situation or a cause - can make us think, how it can be transformed into a question in order to suspend the 'and thus' of rational debate and slow down reasoning" (Schildermans 2019: 158).

Workload allocation models (WAMs) are now widely used in many UK universities to allocate time spent on teaching, administration, research and management. As Papadopoulos (2017:513) points out, although they refer to time, "duration is not the principle governing the allocations of work; expectations are framed in terms of either teaching requirements (contact hours or students) or outputs ('three quality publications')". WAMs are thus an example of a performative technology, the basic rationale for which is to make the future manageable in advance, and to monitor the activities of academic staff in an environment in which they play a key role in transforming it into a techno-rational dystopia. WAMs imply a process of "activity planning" that is inimical to thinking, as thinking does not proceed in a linear fashion. As Jabès (1996: 58) explains in characteristically gnomic fashion, "thought forms by intertwining what is thought - its boiling past - and what is unthought, its problematic future: a plain knot, or one with a brand name". To enunciate the acronym WAM is to move beyond clean, detached rationality, to dispense with affect and uncertainty and to commit an act of symbolic violence. WAM!

What an Almighty Mess! This became our placeholder, our subversive reconfiguration of WAM. It is our way of questioning what has been made to appear as self-evident from an outside-in perspective, but is not even remotely self-evident to us, at least not from an inside-out perspective as three women in a boat. As Schildermans (2019: 159) explains, seeing the problem in this latter way 
requires us to ward off all transcendent reasons that could be given, and engage with all the divergent dimensions the problem plays into, to effectuate a transformation that takes up these reasons in an always local, situated, precarious, and partial response (our emphasis).

Despite our protestations about the limitations of outside-in perspectives, we have dwelt upon these rather longer than we had originally intended. This is perhaps an inevitable consequence of the culture of performativity that inflects the work even of those who display resistance.

Time is running on. It's a rainy Thursday evening in mid-September. We need to make our way to Nini's consulting room for a from-the-inside-out perspective on WAM. As we shall see, Nini is attempting to "stay with the trouble". Here we afford the reader privileged access to a space that hovers between the public and the private. We follow her into the consulting room and see how she attempts to address the consequences of the whole-sale adoption of WAMs on individual subjectivities.

\section{Working with "Wammie"}

Really this piece of work has not been giving Nini much joy; for once a week she will have Wammie on the couch - a young, highly intellectual academic who was brought to her consulting room by, as Nini recalls his self-diagnosis, existential pangs of "discontent complex" and "intolerance of trivialities". Once a week she listens to his complaints of how things are not happening fast enough, and the myriad of nuances that get in the way. There is always one thing or another that gets in his way.

On this particular Thursday, Wammie, as usual, comes straight to therapy after work in a state of irritation. Nini's comments that aim towards helping him to slow down, to connect with his feelings and to reflect more deeply, seem to be experienced as just one of the nuances as he charges ahead, leaving Nini behind.

Nini: This irritation of distraction at work seems well-rehearsed. I've heard a lot of it. For the past three months you have been telling me how you would have done a lot more if it was not for this or that. And, I...

Wammie: And you seemed, sorry to say, indifferent to my suffering. In fact, it's been on my mind to discuss ending this. I am not sure it is working for me. It costs me time and money and all I do is just lie around here and talk. I just can't see the point of continuing to invest in this.

Nini: I suppose I am not surprised you raised this with me today, Wammie. I have been wondering how you have been experiencing me during our time together. I have often felt that you were expecting progress to happen at an impossible 
pace, when what you are hoping to achieve through therapy - to be rid of those "pangs" - is a matter of great complexity. I think those "pangs" are telling us something significant about what is going on in your life right now. I also think that they might be telling us something about how your experiences may be a part of the greater picture of the social world we live in. And yet...

Wammie: I am not here for the story-telling. Logically if I am paying, I need to know what I am getting out of this.

Nini: And you expect I would have that drawn out for you already?

The above exchange seeks to show how and when rationalisation and relationality clash. What may be worth pointing out is that "Wammie" lives in the margin of reality and fiction - he is not "real" in the sense that he does not represent one particular individual client. However, his presence is nevertheless "real" in the sense that it is evoked as a placeholder of figments of a collective of subjectivities that share and express similar struggles. "Wammie", in this sense, is born out of a nuanced response to the banal problematics of contemporary higher education, where productivity and performativity (as we have argued above) triumph over relationality and ethical relations that in this case are anchored deep within the therapeutic work. The therapeutic encounter intentionally stages Wammie's habitual "acting out" of the rigidity of being hyper-rational, efficiency-minded, mechanistically constricted, and dissociated from affective and interpersonal sensitivity and depth. In so doing, it implicates the effects of being "wammed", i.e. as being subjected to external forces (workload allocation, for example) that imbue individual subjectivity with a persecutory consciousness of self-discipline and self-control. This fictitious encounter marks the experiential revelation of how a human body becomes acted upon by the parasitical coercion of WAM, seizing the subject from the inside and subverting any necessity for a reflexive subjectivity to emerge. Time is regarded as something that is outside us, as something that we can waste.

Wammie did not respond. The silence drags on, thickening into an unsettled, murky air in the room. Nini is wondering how the silence is being experienced by Wammiewhat work silence is doing here- if anything.

Wammie: This is absurd! [with a movement that jerks his head up towards the unreachable high ceiling of an old Edinburgh building]

Nini: What is? 
Wammie: You allowing the time to go unused. Having just told you that I have not found my time here useful.

Nini: Silence feels like a waste of time?

Wammie: Yes. All this is a complete waste of time.

Nini: It does not have to be.

Wammie: What are you saying? Nothing gets done, nothing is happening in silence! [the head jerks higher up from the couch this time] I could have brought my work here if you intend just to sit there in silence.

Once again Nini is made to feel very guilty for wasting his time, for being of no use to him, and for creating this futile space of fifty minutes in which the work that gets done is invisible and cannot be captured in numbers, or modulated by the ticking clock. She ponders how, if indeed it is possible at all, she can help Wammie to see that the real problems are not out there to be solved but are here in the room, in the way he relates to her, to time.

Nini: I was just suggesting that a lot can happen in silence, even when it appears as though nothing is being done.

Wammie waits for Nini to go on, as he seemed intrigued by the words "happen" and "done".

Nini: For example, how one might be thinking when not speaking. Like I was, in that silence, wondering how I could have also said to you that to be with someone is not always because there is something to gain. To give attention to another person, sometimes, is just that we care for them ${ }^{2}$. I let the silence do the talking so that I can do the caring.

Wammie seems to be pondering about what has just been said.

2 Here we draw on Simone's Weil (2015 [1970]) philosophy of attention which re-conceives attention-giving as akin to the spiritual task of praying - "a mute prayer, a prayer in act and in silence" (Weil 2015: 100). Attention to another requires an expansive awareness and sensitivity with which we "read" over the threshold of what the other person is going through - an ethical act of stepping out of oneself in order to be drawn into the lived world of the suffering person. It is in this sense that she famously says, "attention is the rarest and purest form of generosity", in a letter to her poet friend, Joë Bousquet (cited in PéTrement 1976: 462). 
Wammie: As good as that sounds, and I am sure you mean well, that does not seem applicable in the real life. I cannot "WAM" the silence, the thinking, the caring into the Time Allocation Model. So, what you are suggesting is barely applicable to my life outside, which means that is of no real use to me. I won't be back next week.

Hartmut Rosa's $(2003,2015)$ concept of social acceleration shows us how time, as a result of trading with the devil of modernity ${ }^{3}$, can never be owned as an individual asset. The practices of allocation of temporal resources (at work, in daily routines, leisure activities) are to a large extent "prescribed by the collective temporal patterns and synchronisation of requirements of society" (Rosa 2015: 9). Our temporal practices of how to use our time and what to spend time on are subject to our involvement in the respective social spheres. All social spheres are lived domains with an implicit temporal rhythm in the background - an invisible clock ticking to an incessant operation of a temporal structure that generates a synchronising pressure to which all members need to adapt. Individuals engage in routines and habitual practices that serve as temporal strategies to be "in sync with" the collective temporal patterns and not to "fall behind", or worse still, to be "out of time". WAM typifies the control of temporal resources by determining individual members as homogenised and governable "Wammies". For Wammies, to keep up, to keep on and to get on in the institutional life means doing what everyone else is doing and remaining a loyal subject to the faceless bureaucrat of numbers. Or as Hannah Arendt (1998 [1958]) puts it, "to submit to the rule by nobody", which seeks to regulate its members by normalising actions and offsetting individual differences within the institution - "to make them behave, to exclude spontaneous action or outstanding achievement" (Arendt 1998: 40). Particularity or uniqueness of individual traits, cultures, developmental stages and needs which give rise to one's natural rhythms are sacrificed to the metronomic beat of numbers.

When rationality trumps relationality, nurturance metamorphoses into nuisance, and time-out is regarded as time-wasted. Through giving attention to Wammie, Nini seeks to illuminate the impact of WAM on the collectives of individuals in her local environment, the University of Edinburgh, as WAM has had a considerable impact upon her own subjectivity. The dialogical exchange with Wammie, as staged above, also speaks to the internal tension in her veins engendered by the clash of rationality and relationality as she juggles her multiple roles as a young academic and psychotherapist. She is "staying with the trouble" as she wrestles with

\footnotetext{
3 Rosa's critical theory on modernity brings a significant reminder that to understand modernity characterising contemporary western societies and its developmental tendencies, we also need to understand how they are underlined by the "specificity, logic, and development of [the] structures of time" (Rosa 2015: 13). "Modernity", as he put succinctly, "is about the acceleration of time" (Rosa 2015: 14). As the acceleration of time gradually becomes too fast for individuals catch up to, the crisis of our time becomes, therefore, just that - "a crisis of time" (Rosa 2015: 15).
} 
the competing demands of producing research "outputs" and caring for herself, with getting things done in time and being in qualitative moments of timelessness. The temporal logic of ensuring that all hours are effectively "used" that governs her working life follows her even as she turns off the lights in her office. It accompanies her wherever she goes; it follows her to her coffee with Annie. So much so that she makes the following declaration to Annie: "I cannot 'WAM' the time I spend having a coffee with you, even though we talk good stuff". WAM follows her home; it ensures that she gets annoyed when her partner interrupts her reading to ask if she would like the mushrooms fixed with couscous or served separately. She exclaims to her partner "I don't have bloody time for this kind of trivial question!" What she said felt wrong, yet she was convinced it was right. But it was the WAM she was so accustomed to hearing that was talking. It was "the cultural self-expression of society" (Rosa 2015: 15) that was coming out through her mouth.

\section{Still seas do skilled sailors make: Elizabeth's story}

Elizabeth's account of her conference experience 4 is a cultural expression of a society that is far removed from the one that is discursively produced by WAM. It relates to a form of academic fellowship that gives the lie to the impression created by WAM that a "uniform representation of the multiple dimensions of academic labour is possible" (Papadopoulos 2017: 514). There was nothing arbitrary about Elizabeth's experience, nor indeed is it confined to or by a particular habitat, in this instance a conference that takes place (and makes space) every summer on a Greek island. Rather she tells of time taken, claimed quietly. Time mattered most in the spaces between moments. Her account is in marked contrast to the experience of one of the respondents in a study of the impact of online technologies on workloads conducted by Tynan et al. (2012). This particular respondent described the operations of models such as WAM as follows: "It's just an arbitrary measure ... you may as well turn around and say your workload reflects how many window panes you've got in your room" (Tynan et al. 2012: 27).

Elizabeth, on the other hand, speaks to the inseparability of ethos and oikos, habit and habitat, in a climate that affords warmth (literally and metaphorically) and presents ample opportunities for living and listening, for caring capably, for nourishment and nurture. Passion could make productivity something rich and luxurious because stimulation co-existed with relaxation without comment. The core values are eagerness and warmth rather than accountability and performance. Paradoxically, the brevity of the presentations at the conference led to expansiveness rather than to contraction and constriction. Here are Elizabeth's words.

\footnotetext{
4 "Philosophy of Education as Lived Experience: navigating between the dichotomies of thought and action", Tilos, Greece, 2-6 July 2019.
} 
Not a morning person, by nature or habit, on Tilos I came to know dawn. In these moments before darkness met light, each necessary and essential, the island was invisible to me yet I was a part of it. My presence mattered. Tilos, in its quiet way, called forth that which I had come to think and talk about. It called on me to care, capably.

It is a testament to the Philosophy of Lived Experience conference how difficult it is to write about. Words fall short or sound sentimental and soft. It is difficult to adequately describe, to capture on the page the cumulative experience days of stimulation, academic and social, and relaxation, professional and personal, create. The effect of being so nourished is both uplifting and edifying. A community of scholars and a community of friends, we were happy and productive together. Everyone was heard, which brought a sense anticipation, a question of when rather than whether, which profoundly changes the conference dynamic for the better I think. All colleagues were called to express and illustrate their passions, where the brevity of the timeframe was best served by careful clear crafting, and the papers consistently met by eagerness and warmth from the audience. The small require care and attention. This particular challenge to be brief and deep and whole was met with innovation and passion.

Tilos is ease. It is to be eased and expansive, to be easy and open and generous. I came away refreshed and re-minded, in body and purpose, and deeply grateful to the thought-full and invigorating organisers who delivered the lightest and most profound lesson in living and listening.

Spontaneity. Ease. Eagerness. Dynamism. Expansiveness. Lightness. Gratitude. Invigoration. Warmth. Passion. Attention. Stimulation. Presence. These are the things that matter most in (academic) life. And they cannot be counted and calibrated. And they cannot be measured and found lacking. They cannot be measured at all.

\section{To sea, three}

As we row the boat away from the sinking ship, preoccupied by assessing the water it takes on, the degree of engorgement, oblivious to its own steady descent, the water laps around us and the sea lulls us into its swirling swell. Our rhythm is all that matters. It brings us closer together and creates space between us and the crashing rocks on a distant shore. The horizon cuts across the sky like a blade. As day shades into night, the horizon fades entirely from view. The showmanship of the setting sun cedes to darkness, and there is a gradual merging of sea and sky. What was once straight, strong and complex is all brushed velvet, a deeper richer face.

Perhaps this is what it is to think, together.

\section{Acknowledgements}

We are grateful for the contribution of Hans Schildermans and other colleagues and friends who attended the annual conference on "Philosophy of Education as Lived Experience: navigating the dichotomies between thought and action" on the island of Tilos, Greece. Particular thanks are due to Tomasz Szkudlarek 
and Maria Mendel of the University of Gdańsk for their presence on Tilos over the years, and for drawing to our attention the theme of this issue of Ars Educandi this summer.

\section{Literature}

Arendt H., 1998, The Human Condition, Chicago: University of Chicago Press.

Ball S., 2000, Performativities and fabrications in the education economy: towards the performative society?, Australian Educational Researcher, 27(2).

Ball S., 2001, Performativities and fabrications in the education economy: towards the performative society [in:] D. Gleeson and C. Husbands (eds) The Performing School. Managing Teaching and Learning in a Performance Culture, London: Routledge Farmer.

Ball S., 2003, The teacher's soul and the terrors of performativity, Journal of Education Policy, 18.

Ball S., 2008, Performativity, privatisation, professionals and the State [in:] B. Cunningham (ed) Exploring Professionalism, London: Institute of Education.

Ball S., 2012, Performativity, commodification and commitment: an I-Spy guide to the neoliberal university, British Journal of Educational Studies, 60(1).

Ball S., 2015, Living in the neo-liberal university, European Journal of Education, 50(3).

Collini S., 2012, What are Universities for?, London: Penguin Books.

Day S., Pirrie A., 2019, Tales from the Matrix: student satisfaction as a form of governmentality. Paper presented at the European Conference for Educational Research, Hamburg, 3 September 2019.

Dylan B., 1963, 'The Times They are A’Changin'. (Witmark Demo, 1963) Lyrics @ Sony/ ATV Music Publishing LLC, Audiam, Inc.

Englund H., Gerdin J., 2019, Performative technologies and teacher subjectivities: a conceptual framework, British Educational Research Journal, 45(3).

Foucault M., 1993, About the beginning of the hermeneutics of the self: two lectures at Dartmouth, Political Theory, 21(2).

Haraway D., 2016, Staying with the Trouble. Making Kin in the Chthulecene, Durham, NC: Duke University Press.

Jabès E., 1996, The Little Book of Unsuspected Subversion, Stanford, CA: Stanford University Press.

Kafka F., 1996, Der Aufbruch, in R. Hermes, (ed) Franz Kafka Die Erzählungen und andere ausgewählte Prosa, Frankfurt am Main: Fischer Taschenbuch Verlag.

O’Brien E., 2019, 'To care, capably' Presentation at the ninth annual Tilos conference, Philosophy of Education as Lived Experience: navigating the dichotomies between thought and action, Tilos, Greece, 6-9 July 2019.

Papadopoulos A., 2017, The mismeasure of academic labour, Higher Education Research and Development, 36(3).

PéTrement S., 1976, Simone Weil: A Life. New York: Pantheon Books.

Pirrie A., 2019, Virtue and the Quiet Art of Scholarship: reclaiming the university. London: Routledge.

Pirrie A., Day S., 2019, Reflective practice and student satisfaction: never the twain shall meet? European Educational Research Journal, 18(4). 
Pirrie A., Fang N., 2019, Venturing from home: writing (and teaching) as creative-relational inquiry for alternative educational futures, Forum, Qualitative Social Research (forthcoming).

Raaper R., 2016, Academic perceptions of higher education assessment processes in neoliberal academia, Critical Studies in Education, 57(2).

Raaper R., 2017, Tracing assessment policy discourses in neoliberalised higher education settings, Journal of Education Policy, 32(3).

Raaper R., 2018, 'Peacekeepers' and 'machine factories': tracing Graduate Teaching Assistant subjectivity in a neoliberalised university, British Journal of Sociology of Education, 39(4).

Raaper R., 2019, Students as consumers? A counter perspective from student assessment as a disciplinary technology, Teaching in Higher Education, 24(1).

Rosa H., 2003, Social Acceleration: Ethical and Political Consequences of a Desynchronized High-Speed Society, Constellations, 10.

Schildermans H., 2019, Making a University. Introductory Notes on an Ecology of Study Practices. Unpublished PhD thesis, KU Leuven, Belgium.

Shepherd S., 2017, Managerialism: an ideal type, Studies in Higher Education, 10.1080/03075079.2017.1281239

Smith R.D., 2016, The virtues of unknowing, Journal of Philosophy of Education, 50(2).

Stengers I., 2005, The cosmopolitical proposal, in B. Latour and P. Weibel (eds) L. Carey-Libbrecht (trans) Making Things Public. Atmospheres of Democracy, Cambridge, MA: The MIT Press.

Tynan B., Ryan W., Hinton L., Lamont A., 2012, 'Out of hours': Final Report of the project e-Teaching leadership. Planning and implementing a benefits-oriented costs model for technology enhanced learning, Sydney: Australian Learning and Teaching Council.

Vlieghe J., Zamojski P., 2017, The Event, the Messianic and the Affirmation of Life. A Post-critical Perspective on Education with Agamben and Badiou, Policy Futures in Education, 15.

Ward S.C., 2011, The machinations of managerialism: New Public Management and the diminishing power of professionals, Journal of Cultural Economy, 4(2).

Weil S., 2015, First and Last Notebooks: Supernatural Knowledge. Eugene, OR: Wipf and Stock. Whitehead A.N., 1929, The Aims of Education and Other Essays, New York, NY: The Free Press.

\section{Abstract}

This article takes a sideways look at conventional academic practices, with a view to re-instating ethical relations as the core of scholarly inquiry and revitalising interdisciplinary collaboration between academics at different stages of their careers.

Keywords

ethical relations, scholarly collaboration, workload allocation models 